\title{
Predicting Hearing Aid Gain Values for Enhancing the Speech Intelligibility Using Correlation Algorithm
}

\author{
S. Rajkumar ${ }^{1, *}$, S. Muttan ${ }^{2}$, V. Jaya ${ }^{3}$, S.S.Vignesh ${ }^{3}$ \\ ${ }^{1}$ Department of Electronics and Communication Engineering, Kings Engineering College, India \\ ${ }^{2}$ Department of Electronics and Communication Engineering, Anna University, India \\ ${ }^{3}$ Madras Medical College \& Rajiv Gandhi Government Hospital, India
}

Copyright (C) 2015 by authors, all rights reserved. Authors agree that this article remains permanently open access under the terms of the Creative Commons Attribution License 4.0 International License

\begin{abstract}
The tranquil solution for the hearing impaired subjects to get rid of the impairment is to wear the appropriate hearing aid to increase the hearing level and clarity of the perceived speech. Though the present day hearing aids are inbuilt with a suitable noise removing algorithm to get a clear speech signal, the satisfaction among the users is low. The satisfaction of the hearing aid users will be enhanced only with the fixation of appropriate Real Ear Insertion Gain (REIG) values for different frequency bands of the perceived speech signal. Various prescriptive procedures were developed so far in prescribing these values. But, the strenuous task for the audiologists is in selecting the best procedure and to suggest required modifications. The present work focuses this problem faced by the audiologists by analyzing the various technical snags and arrived with suitable solutions. In the present work, an expert system was developed to predict gain values without the need of the prescriptive procedures and reduced the trial and error time of the audiologists. A gain suggestion database of the satisfied subjects was developed, and later it was used by the correlation algorithm in the gain prediction process. The successful gain suggestions of the most correlated subject for different frequencies in the database are recommended for the new subject. The developed expert system was validated by performing hearing aid trials with 256 hearing impaired subjects and $93.7 \%$ of them received satisfaction. The successful gain suggestions made by the expert system are stored continuously to strengthen the database, so as to recommend the most appropriate gain values for the new subject.
\end{abstract}

Keywords Prescriptive Procedure, Speech Discrimination Score, Pure Tone Average, Gain, Sound Pressure Level, Frequency Bands

\section{Introduction}

The hearing capability of an individual is assessed by performing pure tone and speech audiometric test. In pure tone audiometric test, tones of specific octave frequencies are generated in the audiometer and fed to the testing subject to assess the hearing level by measuring the minimum threshold of hearing. In speech audiometric test, the stored standard test words are presented to the subject and asked to repeat it to assess the speech intelligibility of them. The ear is a complicated organ in term of the process as it applies to the different perceived sound frequencies $[1,2]$. In case, if ear fails to make this process effectively, modern digital hearing aids are capable of suitably amplify the perceived signal using the algorithm inbuilt, to satisfy the hearing impaired subjects [3]. The electro acoustical characteristics of the hearing aid have to be modified properly, so as to enhance the satisfaction level of different types of hearing impaired subjects [4-9]. Prescriptive procedures are standard set of protocols developed by different researchers in the past three decades, to suggest the suitable Real Ear Insertion Gain (REIG) values for different frequency bands of the digital hearing aid [10]. Though many linear and nonlinear prescriptive procedures were developed so far, the most successful prescriptive procedures in suggesting appropriate gain values include NAL-R, NAL-RP, POGO II, DSL I/O, FIG6, IHAFF, FIG6, NAL-NL1 and NAL-NL2. These procedures are classified either as procedure based on loudness equalization or based on speech intelligibility. Speech Discrimination Score (SDS) is the most important parameter calculated in speech audiometric test, which is the ratio of correctly identified words with that of total words presented to them, and it should be 100 for the most satisfied subjects. The satisfaction level of the hearing impaired subjects was concluded by performing the speech audiometric test with them. The test was conducted after fixing with the hearing aid gain suggestions recommended by each prescriptive procedure. The SDS value was calculated for each procedure, and the procedure which gave maximum value of SDS was concluded as better prescriptive procedure for the specific type of hearing loss. But the 
problem with the prescriptive procedures is, each procedure suggest different solution for the same subject. The audiologists find it tough to identify the correct solution. Hence, in the present work, the various difficulties faced by the audiologists were analyzed and attempt was made to find a solution. In that, initially, it was aimed to identify the best procedure which suits to the population under study. Hearing aid trials were made to the impaired subjects fitted with gain values recommended by different successful prescriptive procedures. Based on the test conducted with population under study and with the SDS value calculated, it was found that, the procedures based on speech intelligibility from NAL acoustic laboratories NAL-R, NAL-NL1 and NAL-NL2 gave better satisfaction among all the prescriptive procedures [11 - 14]. The aim of the present work is to analyze the standards and parameters used in the various linear and nonlinear prescriptive procedures, by performing proper audiological investigations with the hearing impaired subjects, so as to develop an expert system to predict appropriate gain values for digital hearing aid. The expert system proposed successful gain suggestions for the subjects not satisfied with the gain recommendations of any of the existing prescriptive procedures. The recommended successful gain suggestions of the satisfied subjects are stored in the database and used by the correlation algorithm to recommend gains for the new subject. The important parameters used in the correlation algorithm are minimum threshold of hearing in dBHL for a particular octave frequency, Pure Tone Average (PTA) in dBHL which is an average of minimum threshold of hearing measured at three frequencies $500 \mathrm{~Hz}, 1000 \mathrm{~Hz}$ and $2000 \mathrm{~Hz}$, Sound input level in dBSPL for the hearing aid, and age of the subject. The sound input levels used in the study are 40dBSPL, 60dBSPL and 80dBSPL.SPL means Sound Pressure Level. Since the gain values suggested to the new subject are from the satisfied gain suggestion database, the success rate of the expert system in predicting gain suggestions improved.

\section{Material and Methods}

The present work was carried out in the Department of speech and hearing of Government hospital, Chennai for a study population of 368 subjects after obtaining the ethical clearance from the institutional ethical committee of the hospital. The hearing impaired subjects were also obtained with proper informed consent form. After the conduction of pure tone audiometric test with them, they were grouped as normal and abnormal hearing condition. 256 subjects were identified as having abnormal hearing condition. They were suffering either with conduction loss or with sensorineural hearing loss. The impaired subjects subsequently underwent speech audiometric test. Words from languages, English and Tamil as recommended by Indian Speech Hearing Association (ISHA) were used in the speech audiometric test. The subjects visiting the hospital found it difficult to understand the NAL test words in English and in turn the
SDS value obtained was also less compared to the SDS value arrived while using Tamil words as clearly indicated in table 1 for a sample of subjects. Since the aim of the work is to maximize speech intelligibility, the analysis of the frequency spectrum of the recommended words was performed to ascertain them as equivalent with that of the standard test words used. SDS value obtained without using a hearing aid is termed as unaided score. Subsequently, the hearing impaired subjects were fitted with the proper hearing aid and tested with the gain recommendations for different frequencies suggested by any one of the existing procedure. Hearing aids used in the study are:

- Siemens Intuis life

- Intuis SP DIR

Table 1. SDS value obtained from a sample of subjects with the words presented in English and Tamil and in both unaided and aided condition

\begin{tabular}{|c|c|c|c|c|c|}
\hline Age & Sex & $\begin{array}{c}\text { Unaided } \\
\text { English }\end{array}$ & $\begin{array}{c}\text { Aided } \\
\text { English }\end{array}$ & $\begin{array}{c}\text { Unaided } \\
\text { Tamil }\end{array}$ & $\begin{array}{c}\text { Aided } \\
\text { Tamil }\end{array}$ \\
\hline 74 & $\mathrm{M}$ & 52 & 62 & 60 & 78 \\
\hline 65 & $\mathrm{~F}$ & 52 & 64 & 65 & 80 \\
\hline 75 & $\mathrm{~F}$ & 40 & 46 & 50 & 56 \\
\hline 67 & $\mathrm{M}$ & 40 & 55 & 45 & 80 \\
\hline 67 & $\mathrm{M}$ & 70 & 80 & 80 & 85 \\
\hline 65 & $\mathrm{~F}$ & 58 & 70 & 74 & 74 \\
\hline 76 & $\mathrm{M}$ & 42 & 50 & 52 & 54 \\
\hline 35 & $\mathrm{~F}$ & 64 & 70 & 75 & 80 \\
\hline 75 & $\mathrm{~F}$ & 62 & 75 & 75 & 80 \\
\hline
\end{tabular}

Of the hearing impaired subjects tested with the hearing aid fitting, only 88 subjects obtained maximum satisfactory performance with the gain suggestions based on NAL procedures. To the remaining unsatisfied subjects, the increase in the SDS value and also enhancement in the speech intelligibility only when the audiologist or the expert system made appropriate changes in the gain settings. The audiologist presented a list of questions as shown below to the impaired subjects. The necessary modifications in the gain suggestions were made by considering the reply, the audiologist received from the hearing impaired subjects for the prepared questionnaire. The altered gain values are stored in the system database so that it can be used for recommending gain values to the new subject $[15,16]$.

Questionnaire for hearing impaired subjects

\section{Hearing Details:}

Do you work in noisy environment? : : Yes/No

If yes, what is the type of noisy condition ?:

Categorize your living environment? : Silent/less Noise/ more noise

Is there a family history of hearing loss? : Yes/No

What is your mother tongue? : Tamil/English/Others

If others, mention the language

Mention how long you have hearing loss

The questions below were queried after fixed with the proper hearing aid first with the gain recommendations of 
NAL procedure and then with the gain suggestions of expert system.

Are you satisfied by the first set of gain formula?

Fully/Partly/Not satisfied

Did you hear muffling voice? : Louder/Slightly/Normal

Did you perceive speech with equal loudness? : Yes/No

Did you able hear intelligible speech?

Yes/Partly/No

Did you hear a hissing sound? : Louder/Slightly/Normal

Did you hear an unwanted noise? : Y Yes/No

Are you satisfied with the change in gain values? :

Yes/Partly/No

The gain suggestions for the $250 \mathrm{~Hz}$ frequency signal was reduced, if the subject complained muffling voice and it was increased, if the subject found hard to hear the words related to the low frequency notes. The gain for the frequencies $500 \mathrm{~Hz}, 1000 \mathrm{~Hz}$ and $2000 \mathrm{~Hz}$ was reduced, if the subject had the difficulty in understanding the speech. If they complain about the audibility of the speech, the gain for these frequencies was increased, because of the fact that majority of speech frequencies lies in these range of frequencies. The gain for the frequencies $4000 \mathrm{~Hz}$ and $6000 \mathrm{~Hz}$ were reduced, if the subject experienced hissing noise or screaming noise, and it was increased, if they fail to hear high frequency sounds.

\section{Gain prediction using correlation algorithm}

The concept behind this technique is to find the successful gain values of the correlated subject who has same audiological parameters as that of the new subject, and proposes it to the subject requires gain suggestions. The important values considered as input parameters to calculate the correlation coefficient are:

- minimum threshold of hearing in $\mathrm{dBHL}$ for a particular octave frequency.

- PTA in dBHL, an average of minimum threshold of hearing measured at three frequencies $500 \mathrm{~Hz}, 1000 \mathrm{~Hz}$ and $2000 \mathrm{~Hz}$ used to identify the average hearing level of an individual.

- sound input level in dBSPL for the hearing aid. The levels used in the study are 40dBSPL, 60dBSPL and 80dBSPL.SPL means Sound Pressure Level.

- age of the subject

The two dimensional correlation coefficient is calculated by using the algorithm given in the equations 1 and 2

$$
\begin{gathered}
r=\frac{\operatorname{COV}(A, B)}{\sigma_{A} \sigma_{B}} \\
r=\frac{\sum_{m} \sum_{n}\left(A_{m n}-\bar{A}\right)\left(B_{m n}-\bar{B}\right)}{\sqrt{\sum_{m} \sum_{n}\left(A_{m n}-\bar{A}\right)^{2}} \sqrt{\sum_{m} \sum_{n}\left(B_{m n}-\bar{B}\right)^{2}}}
\end{gathered}
$$

The following steps were followed in suggesting appropriate gain values for the new subject who requires gain suggestion with the expert system:

Step1: The subjects with the minimum threshold of hearing at the specific tested frequency exactly same as that of the new subject is found out in the successful gain suggestion database.

Step 2: If there is no subject exactly matches with the threshold value of the new subject, those subjects with the nearest values will be shortlisted.

Step 3: The correlation value of those subjects with the new subject required gain suggestion is calculated using the equation 2 . The parameters, minimum threshold of hearing at the tested frequency, lowest PTA value, unaided score and age of the new subject and the same parameters of short listed subjects were used in the calculation.

Step 4: The subject calculated with higher correlation value is considered to be the most correlated subject with the new subject for that particular tested frequency. The successful gain suggestions of the correlated subject for three different sound input levels 40dBSPL, 60dBSPL and $80 \mathrm{dBSPL}$ are recommended to the new subject.

Step 5: Similar predictions were made for the remaining tested frequencies, and the successful gain suggestions were recommended to the new subject.

Step 6: The gain suggestions were incorporated in the hearing aid and the subject was tested for speech discrimination threshold test, and the SDS value was calculated and compared with the unaided score i.e. SDS value obtained without the usage of hearing aid.

\section{Results and Discussion}

The analysis of successful gain values prescribed to different types of hearing impaired subject explained in this section. The analysis of the gain suggestions made with different frequencies is mandatory to know the significance of frequency dependency of the presented sound signal. In the case of $250 \mathrm{~Hz}$, the minimum threshold of hearing of the subjects considered for comparison is $40 \mathrm{dBHL}$ i.e. the three subjects having 40dBHL as their minimum threshold of hearing shown in figure 1 . The plot is mapped between the gain suggestions recommended for the considered subjects with the lowest PTA value of the subject and also to the three sound input levels under two different settings. The first setting is the gain suggestions made with the better fit procedure and other is with the gain suggestions of the expert system termed as preferred fit procedure. The analysis made as follows. 


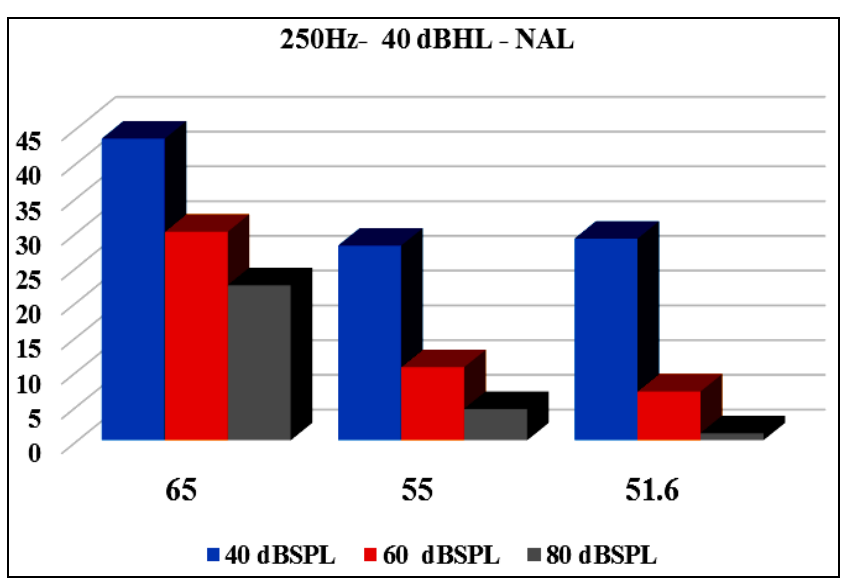

(a)

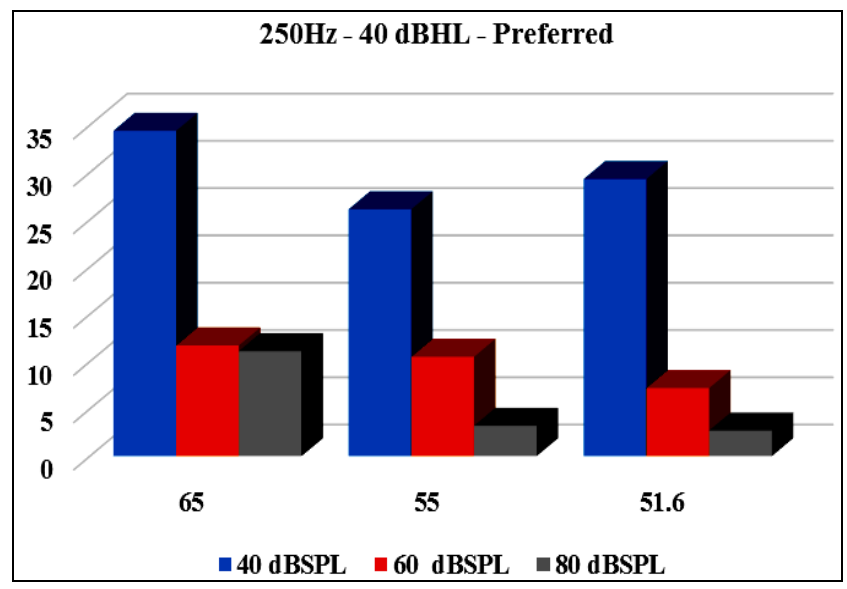

(b)

Figure 1. Gain suggestions for the frequency $250 \mathrm{~Hz}$ with $40 \mathrm{dBHL}$ as minimum threshold of hearing of NAL procedure (a) and Preferred setting (b)

\section{Subject 1: Lowest PTA is 65dBHL}

Sound input level in $\mathrm{BBSPL}$.

Gain suggested by

NAL procedure in dBSPL: $\quad \begin{array}{llll}43.4 & 30 & 22.3\end{array}$

Gain suggested by

The expert system in dBSPL: $\quad 34.4 \quad 11.7 \quad 11.1$

The unaided score for the subject was 70 and the score obtained after fixing with hearing aid based on the NAL recommendations was 78 . The subject with preferred gain setting the SDS value was enhanced to 86 . The subject was recommended with reduced gain values than that of NAL gain recommendations because he complained about muffling voice.

\section{Subject 2: Lowest PTA is 55dBHL}

\begin{tabular}{lccc}
$\begin{array}{l}\text { Sound input level in dBSPL: } \\
\text { Gain suggested by }\end{array}$ & 40 & 60 & 80 \\
$\begin{array}{l}\text { NAL procedure in dBSPL: } \\
\begin{array}{l}\text { Gain suggested by } \\
\text { the expert system in dBSPL: }\end{array}\end{array}$ & 28.1 & 10.5 & 4.5 \\
\hline
\end{tabular}

The unaided score for the subject was 70 and the score obtained with NAL setting was 70 and with the preferred setting the score was 80 . The subject has not obtained an increase in the NAL setting score, whereas in the preferred setting the score increased by 10 .

Subject 3: Lowest PTA is 51.6dBHL

\begin{tabular}{lccc}
$\begin{array}{l}\text { Sound input level in dBSPL: } \\
\text { Gain suggested by }\end{array}$ & 40 & 60 & 80 \\
$\begin{array}{l}\text { NAL procedure in dBSPL: } \\
\begin{array}{l}\text { Gain suggested by } \\
\text { the expert system in dBSPL: }\end{array}\end{array}$ & 29 & 7 & 1 \\
\hline
\end{tabular}

The gain suggested in the preferred setting was very minimally higher than the NAL recommendations in all the three input levels. The unaided score for the subject was 65 and the score obtained with NAL setting was 70 and with the preferred setting the score was 80 . Though the score was enhanced in the NAL settings, still there was a considerable rise in the preferred gain settings. In all the three cases, in the preferred setting, the score was enhanced over the score obtained with NAL setting and enhancement in speech intelligibility was achieved. At $250 \mathrm{~Hz}$ as the PTA value of the subject increased, the subject requires less gain recommendations than it was suggested by NAL procedure to get an enhanced score. But for the subjects having lower PTA value for a minimal increment in the gain settings produced a reasonable appreciation in the SDS value obtained.

- Five different subjects having $45 \mathrm{dBHL}$ as a minimum threshold of hearing in $500 \mathrm{~Hz}$ were considered for comparison and the gain suggestions are shown in table 2. Similar to $250 \mathrm{~Hz}$, the gain for $500 \mathrm{~Hz}$ sound signal was decreased minimally for the subjects having higher PTA value than $45 \mathrm{dBHL}$ to get satisfaction, whereas for the subjects having a lower PTA value the gain was marginally raised to get an enhanced score because of the complaint of muffling voice and difficulty in low frequency hearing.

- The subjects have 50dBHL as a minimum threshold of hearing in the frequency $1000 \mathrm{~Hz}$ were considered for comparison, and the analysis can be made from the gain suggestions shown in table 3 . The modification required in the gain value is very minimal for $1000 \mathrm{~Hz}$ i.e. the gain suggestions in the preferred setting almost matches with the gain recommendations of NAL procedure.

- In $2000 \mathrm{~Hz}$, the subjects having a minimum threshold of hearing 55dBHL were considered for comparison and the gain suggestions are given in table 4 . In $2000 \mathrm{~Hz}$ the gain in the preferred setting was increased over the NAL recommendations if the unaided score is less than 70 whereas it was decreased if the unaided score is more than 70 . If the subject is having unaided score less than 70 then the audibility is a serious concern.

- The subjects having a minimum threshold of hearing $70 \mathrm{dBHL}$ in $4000 \mathrm{~Hz}$ were considered for comparison and the suggested gain for the $4000 \mathrm{~Hz}$ signal is shown in table 5. The gain suggestions for the preferred setting 
were decreased to get enhanced satisfaction with the hearing aid users. Because the subjects were complained about hissing voice. Whereas the subjects having lower PTA value required increase in the gain values more than NAL recommended gains.

- Four different subjects having 90dBHL as a minimum threshold of hearing in $6000 \mathrm{~Hz}$ were considered for comparing their gain suggestions and shown in figure 2 . An increase in gain value of $8.9,10.2$ and $12 \mathrm{dBSPL}$ over the NAL gain suggestions for the subject having PTA value 55dBHL didn't succeed in producing an enhanced score over the score 80 obtained with the NAL gain setting. The subject complains about audibility i.e. clarity of words. As with the gain analysis, the gain in the preferred setting was normally increased for the $6000 \mathrm{~Hz}$ sound signal irrespective of the lowest PTA value to obtain a reasonable increase in the SDS value.

Table 2. Gain suggestions in dBSPL for different sound input levels of $500 \mathrm{~Hz}$ signal in NAL setting and preferred setting.

\begin{tabular}{|c|c|c|c|c|c|c|c|c|c|c|}
\hline \multirow{2}{*}{$\begin{array}{c}\text { Sound input } \\
\text { level in } \\
\text { dBSPL }\end{array}$} & \multicolumn{6}{|c|}{ NAL setting } & \multicolumn{5}{c|}{ Preferred setting } \\
\cline { 2 - 11 } & $\mathbf{6 5}$ & $\mathbf{5 5}$ & $\mathbf{5 0}$ & $\mathbf{4 6 . 6}$ & $\mathbf{4 3 . 3}$ & $\mathbf{6 5}$ & $\mathbf{5 5}$ & $\mathbf{5 0}$ & $\mathbf{4 6 . 6}$ & $\mathbf{4 3 . 3}$ \\
\hline $\mathbf{4 0}$ dBSPL & 41.4 & 28.2 & 22 & 27.1 & 18.6 & 32.6 & 31 & 21.2 & 14.1 & 21.9 \\
\hline $\mathbf{6 0}$ dBSPL & 31.5 & 11 & 2.2 & 7.2 & 4.4 & 10.8 & 10.4 & -3.1 & -9.1 & 12.7 \\
\hline $\mathbf{8 0}$ dBSPL & 24.3 & -0.5 & 0.7 & 7.3 & -0.4 & 8.4 & 4.7 & -9 & -4.1 & 9.1 \\
\hline
\end{tabular}

Table 3. Gain suggestions in dBSPL for different sound input levels of $1000 \mathrm{~Hz}$ signal in NAL setting and preferred setting.

\begin{tabular}{|c|c|c|c|c|c|c|c|c|}
\hline \multirow{2}{*}{$\begin{array}{c}\text { Sound input } \\
\text { level in dBSPL }\end{array}$} & \multicolumn{6}{|c|}{ Nowest PTA in dBHL } \\
\cline { 2 - 10 } & $\mathbf{6 5}$ & $\mathbf{6 2 . 3}$ & $\mathbf{5 1 . 6}$ & $\mathbf{5 0}$ & $\mathbf{6 5}$ & $\mathbf{6 2 . 3}$ & $\mathbf{5 1 . 6}$ & $\mathbf{5 0}$ \\
\cline { 2 - 10 } & 30.3 & 36.1 & 26 & 15.9 & 24.8 & 34.3 & 24.2 & 15.7 \\
\hline $\mathbf{4 0}$ dBSPL & 22.6 & 27.2 & 12 & 8.3 & 17.2 & 26 & 14.6 & -0.3 \\
\hline $\mathbf{6 0}$ dBSPL & 15.4 & 1.5 & 4 & 0.6 & 9.5 & 20.4 & 6.8 & -8.9 \\
\hline $\mathbf{8 0}$ dBSPL & & & & & & & & \\
\hline
\end{tabular}

Table 4. Gain suggestions in dBSPL for different sound input levels of $2000 \mathrm{~Hz}$ signal in NAL setting and preferred setting.

\begin{tabular}{|c|c|c|c|c|c|c|c|c|}
\hline \multirow{2}{*}{$\begin{array}{c}\text { Sound input } \\
\text { level in dBSPL }\end{array}$} & \multicolumn{6}{|c|}{ NAL setting } & \multicolumn{5}{c|}{ Preferred setting } \\
\cline { 2 - 10 } & $\mathbf{6 1 . 6}$ & $\mathbf{5 6 . 6}$ & $\mathbf{5 0}$ & $\mathbf{4 0}$ & $\mathbf{6 1 . 6}$ & $\mathbf{5 6 . 6}$ & $\mathbf{5 0}$ & $\mathbf{4 0}$ \\
\hline & 15 & 15.4 & 15.8 & 18 & 17.4 & 16.5 & 7.9 & 25.4 \\
\hline $\mathbf{4 0}$ dBSPL & 8 & 8.4 & 8.7 & 14 & 7.8 & 8.6 & -0.5 & 22.3 \\
\hline $\mathbf{6 0}$ dBSPL & 4.5 & 3.8 & 3.2 & 11 & 4.5 & 3.9 & -5.7 & 15.4 \\
\hline $\mathbf{8 0}$ dBSPL & & & & & & & & \\
\hline
\end{tabular}

Table 5. Gain suggestions in dBSPL for different sound input levels of $4000 \mathrm{~Hz}$ signal in NAL setting and preferred setting.

\begin{tabular}{|c|c|c|c|c|c|c|c|c|}
\hline \multirow{2}{*}{$\begin{array}{c}\text { Sound input } \\
\text { level in dBSPL }\end{array}$} & \multicolumn{6}{|c|}{ NAL setting } & \multicolumn{5}{c|}{ Preferred setting } \\
\cline { 2 - 10 } & $\mathbf{6 0}$ & $\mathbf{5 1 . 6}$ & $\mathbf{5 0}$ & $\mathbf{4 6 . 6}$ & $\mathbf{6 0}$ & $\mathbf{5 1 . 6}$ & $\mathbf{5 0}$ & $\mathbf{4 6 . 6}$ \\
\cline { 2 - 10 } & 28 & 41 & 26.9 & 38.2 & 31.3 & 38.5 & 14.4 & 29.8 \\
\hline $\mathbf{4 0}$ dBSPL & 15 & 33 & 13.9 & 27.3 & 21.7 & 31.8 & 3.6 & 18.8 \\
\hline $\mathbf{6 0}$ dBSPL & 16 & 20 & 9.5 & 21.3 & 23 & 21.9 & 0.1 & 14.4 \\
\hline $\mathbf{8 0}$ dBSPL & & & & & & & & \\
\hline
\end{tabular}


Similar analysis was made for all the values of minimum threshold of hearing in the respective frequencies. The enhanced SDS value i.e. increase in speech intelligibility obtained by different subjects as a sample data is clearly understood from the table 6. The lowest PTA value is nothing but the lowest value of PTA calculated for both the ears. The hearing aid is suggested to better ear only. Similar analysis is made for all the subjects.

Table 6. SDS value obtained by subjects having different lowest PTA value in both NAL and preferred settings

\begin{tabular}{|c|c|c|c|c|c|}
\hline Age & Sex & $\begin{array}{c}\text { Lowest } \\
\text { PTA }\end{array}$ & $\begin{array}{c}\text { Unaided } \\
\text { score }\end{array}$ & $\begin{array}{c}\text { NAL setting } \\
\text { score }\end{array}$ & $\begin{array}{c}\text { Preferred } \\
\text { score }\end{array}$ \\
\hline 59 & M & 63 & 70 & 78 & 86 \\
\hline 47 & M & 70 & 76 & 76 & 80 \\
\hline 65 & F & 62 & 76 & 82 & 92 \\
\hline 64 & M & 52 & 50 & 54 & 66 \\
\hline 76 & M & 47 & 82 & 92 & 96 \\
\hline 65 & F & 50 & 76 & 82 & 88 \\
\hline 38 & F & 40 & 76 & 82 & 90 \\
\hline 64 & M & 65 & 52 & 54 & 66 \\
\hline 63 & M & 55 & 72 & 74 & 80 \\
\hline 70 & M & 43 & 48 & 54 & 62 \\
\hline 60 & M & 50 & 72 & 82 & 90 \\
\hline 72 & M & 47 & 68 & 82 & 92 \\
\hline 78 & M & 80 & 70 & 80 & 80 \\
\hline 70 & F & 55 & 64 & 72 & 80 \\
\hline 57 & M & 63 & 54 & 74 & 82 \\
\hline
\end{tabular}

To conclude, the gain required for $250 \mathrm{~Hz}$ signal in the preferred setting is lesser than NAL prescriptive gain suggestions for the subjects having PTA value higher than $50 \mathrm{dBHL}$ whereas it is more for subjects having PTA higher than 50 . In $500 \mathrm{~Hz}$ the gain required is less than that of NAL recommendations for subjects with PTA value higher than $45 \mathrm{dBHL}$ and it is more for the subjects with lower PTA value. In $1000 \mathrm{~Hz}$ the gain required is more or less same as that of NAL suggestions irrespective of the PTA value. In $2000 \mathrm{~Hz}$ the gain required for subjects having unaided score more than 70 requires lesser gain than NAL recommendations whereas if the unaided score is below 70 the gain required is more than NAL recommendations. For the frequency $4000 \mathrm{~Hz}$ the gain required is lesser than NAL recommended gain values irrespective of the value of PTA. In $6000 \mathrm{~Hz}$ the gain required is more than the NAL recommendations irrespective of the PTA value and minimum threshold of hearing. The subjects having lower PTA value are getting maximum satisfaction. Early identification of hearing loss will give better satisfaction for the hearing aid users [17-20].

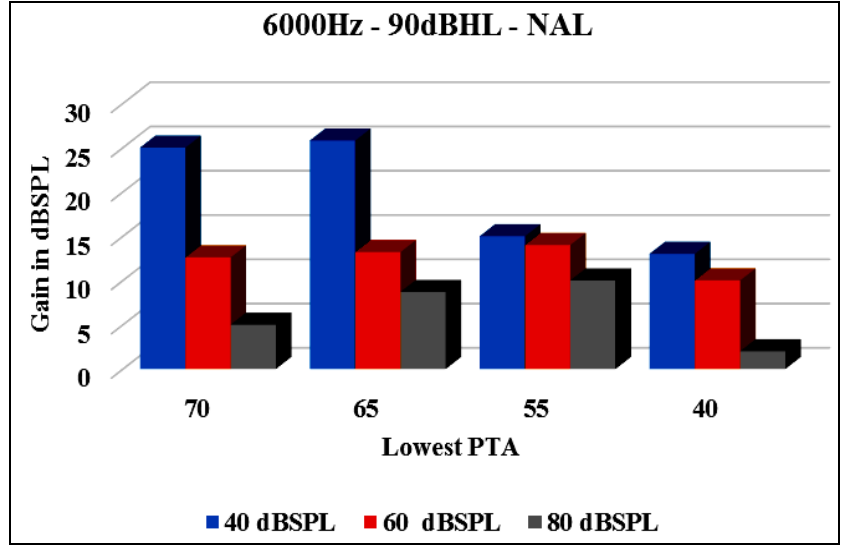

(a)

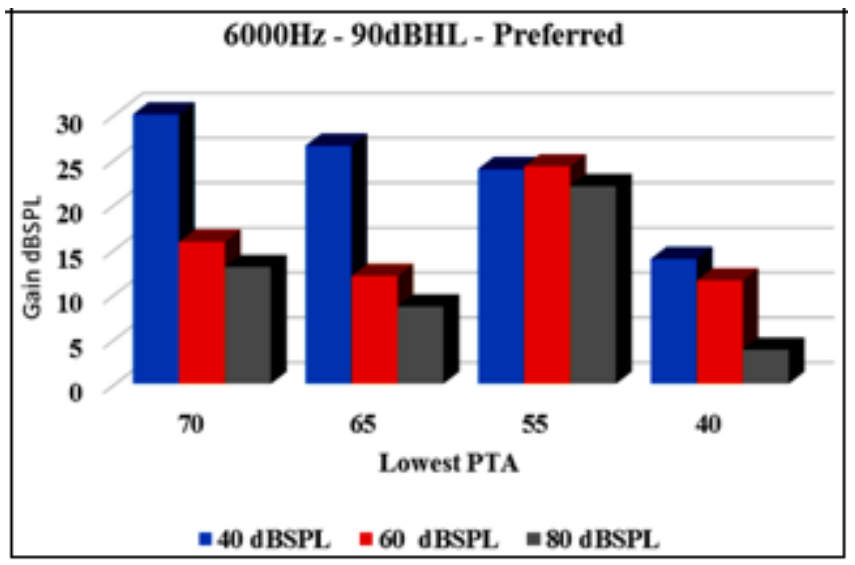

(b)

Figure 2. Gain suggestions of NAL procedure (a) and preferred setting (b) for the frequency $6000 \mathrm{~Hz}$

The hearing aid trials were performed for the 256 hearing impaired subjects. Of which, 88 subjects $(34.4 \%$ of the total 256 subjects) attained satisfaction with the performance of the hearing aid fitted with the gain recommendations suggested by any one of the existing prescriptive procedures. But this process required more number of hearing aid trials to ascertain the satisfaction of the hearing impaired subjects. This process also required the precious time of the audiologists to try with different better prescriptive procedures before concluding the right procedure. An additional of 71 subjects $(27.7 \%)$ received satisfaction, only when the audiologists made necessary corrections in the gain values based on the feedback obtained from the hearing aid users. In the remaining unsatisfied 97 subjects, 81 subjects $(31.6 \%)$ attained maximum satisfaction only with the gain suggestions of the developed expert system in the present work. The appropriate gain prediction of the expert system for the 159 subjects ( 88 subjects received satisfaction with the existing procedure plus 71 subjects received satisfaction with the altered gain values by the audiologists) was also validated As an overall analysis, the expert system predicted appropriate hearing aid gain suggestions for 240 subjects (93.7\% of the total subjects) and it can be understood from the table 7 . The analysis conveyed the significant importance of the expert system in predicting the appropriate gain 
suggestions. The developed expert system reduces the confusion among the audiologists in selecting an appropriate prescriptive procedure. It also reduces the time consumption of the audiologists in altering the gain values. The remaining $6.3 \%$ subjects may attain satisfaction if the expert system is trained with the large database. If the expert system is used continuously and the database gets strengthened by the addition of gain suggestions of many specific impaired subjects, higher efficiency of using this system will be achieved. Hence, the system can be effectively used to carry out audiological investigations and to propose appropriate hearing aid gain suggestions so that the speech intelligibility could be increased.

Table 7. Analysis of satisfied subjects with different methodologies

\begin{tabular}{|c|c|c|}
\hline Methodologies & $\begin{array}{c}\text { Number of } \\
\text { satisfied } \\
\text { subjects }\end{array}$ & $\begin{array}{c}\text { Percentage } \\
\text { of satisfied } \\
\text { subjects }\end{array}$ \\
\hline $\begin{array}{c}\text { Hearing aid trials made using the gain } \\
\text { suggestions of any one of the existing } \\
\text { prescriptive procedures }\end{array}$ & 88 & $34.4 \%$ \\
\hline $\begin{array}{c}\text { Hearing aid trials made with the altered } \\
\text { gain suggestions by the audiologists } \\
\text { based on the feedback from the subject }\end{array}$ & 71 & $27.7 \%$ \\
\hline $\begin{array}{c}\text { Hearing aid trials made with the } \\
\text { predicted gain suggestions by the expert } \\
\text { system }\end{array}$ & 81 & $31.6 \%$ \\
\hline Total & 240 & $93.7 \%$ \\
\hline
\end{tabular}

\section{Conclusions}

An expert system was designed and developed for identifying the hearing loss of an individual and to predict apposite gain values for the different frequency bands of digital hearing aid in a single platform. Since the gain recommended for the new subject is obtained from the database of the verified gain suggestions of the subject having the same type and level of hearing loss, the efficiency of the developed expert system in suggesting appropriate gain values is good. In the 256 hearing impaired subjects underwent hearing aid trials with the expert system 240 subjects $(93.7 \%)$ attained maximum satisfaction with the performance of the hearing aid fitted with the gain recommendations of the expert system. Hence, the developed expert system in the present work can be effectually used to mass screen the subjects to identify the hearing loss at the earliest in order to enhance the hearing aid satisfaction. It also suggests most appropriate gain suggestion to the hearing subjects in reducing the trial and error time of the subjects and audiologists.

\section{REFERENCES}

[1] Alessandro Martini, Genes, Hearing and Deafness from Molecular Biology to Clinical Practice, Thomson publishing Services, United Kingdom, 2007.
[2] Fausti, S. A., Henry, J. A., Hett, W. J., Phillips, D. S., Frey, R. H., Noffsinger, D : An individualized, sensitive frequency range for early detection of ototoxicity, Ear and Hearing, 20, 497-505, 1999.

[3] Tucci, D., Merson, M.H., Wilson, B.S.: A summary of the literature on global hearing impairment: current status and priorities for action, Otol Neurotol., (3), 31-4, 2010.

[4] Hojan-Jezierska, D., Hojan, E.: Physica Medica; XX,Supl. 1, $135,2004$.

[5] Hojan, E., Fastl, H., Malenda, J., Hojan-Jezierska, D.: Archives of Acoustics, 30, 1, 2005.

[6] Hojan, E., Furmann, A., Chmielewska, L., Hojan Jezierska, D.: Archives of Acoustics, 30 (Supplement), 245, 2005.

[7] Hojan-Jezierska, D., Stieler, O.M, Polish J. of Environmental Studies, 15, 53, 2006.

[8] Hojan-Jezierska, D., Skrodzka, E., Hojan, E, Polish: J. of Environmental Studies 15, 56, 2006.

[9] Hojan-Jezierska, D., Skrodzka, E., Hojan, E: Archives of Acoustics, Vol. 32, 3, 441, 2007.

[10] Hojan-Jezierskaa, D., Olejnik, A: Effectiveness of selected procedures of hearing aid Adaptation - clinical cases, Acta Physica Polonica A, 118, pp 71-73, 2010.

[11] Rajkumar.S, Muttan.Jaya.V,Vignesh.S.S, Comparative Analysis of Different Prescriptive Formulae Used in the Evaluation of Real Ear Insertion Gain for Digital Hearing Aids, Universal Journal of Biomedical Engineering 1(2): pp. 32-41, 2013 DOI: 10.13189/ujbe.2013.010202.

[12] Dillon, H. NAL-NL1: A new prescriptive fitting procedure for non-linear hearing aids. Hearing Journal, 52(4), 10-16, 1999.

[13] Dillon, H., Keidser, G., Ching, T., Flax, M., Brewer, S. (2004): Development of the NAL-NL2. XIX Australian Audiological Society NationalConference, Sydney, May 2010.11. Katz J. (Ed).

[14] Williams \& Wilkins, Handbook of Clinical Audiology, 4th Edition. Baltimore, London, 2007.

[15] Yanz, J.L., Galster, J: Integrating real-ear measurements into hearing aid fittings, Advance for Audiologists, 38-44, 2008

[16] Yanz, J.L., Pisa, J.F.D., Olson, L: Integrated REM: Real-ear measurement from a hearing aid, Hearing Review, 14(5), 44-51, 2007.

[17] Skarzynski, H: Principles and acoustical foundations of the computer-based hearing screening method, Institute of Physiology and Pathology of Hearing Warsaw, Poland, 2001.

[18] Ykhlef, F., Benzaba, W., Bendaouia, L., Boutaleb, R., Abdelrahmane, B: Computer Audiometer for Hearing Testing, Proceedings of the International Conference on Advances in Electronics and Microelectronics, Valencia, Algeria, IEEE, pp. 111-114, 2008.

[19] Mikolai, T., Mroz, A.C: Innovative clinical tools in the modern era of audiometry. Hearing Review. 17, pp.26-30, 2010 .

[20] Margolis, R.H., Glasberg, B.R., Creeke, S., Moore, B.C: AMTAS: automated method for testing auditory sensitivity: validation studies. Int. J. Audiol. 49(3), pp.185-94, 2010. 